U.S. Department

of Transportation

National Highwory

Traffic Safety

三ㅡ르를을

People saving People

Administration

Wwranteadotgov

DOT HS 809068

June 2000

\title{
Ethnicity and Alcohol-Related Fatalities: 1990 to 1994
}


This publication is distributed by the U.S. Department of Transportation, National Highway Traffic Safety Administration, in the interest of information exchange. The opinions, findings and conclusions expressed in this publication are those of the author(s) and not necessarily those of the Department of Transportation or the National Highway Traffic Safety Administration. The United States Government assumes no liability for its content or use thereof. If trade or manufacturer's names or products are mentioned, it is because they are considered essential to the object of the publication and should not be construed as an endorsement. The United States Government does not endorse products or manufacturers. 


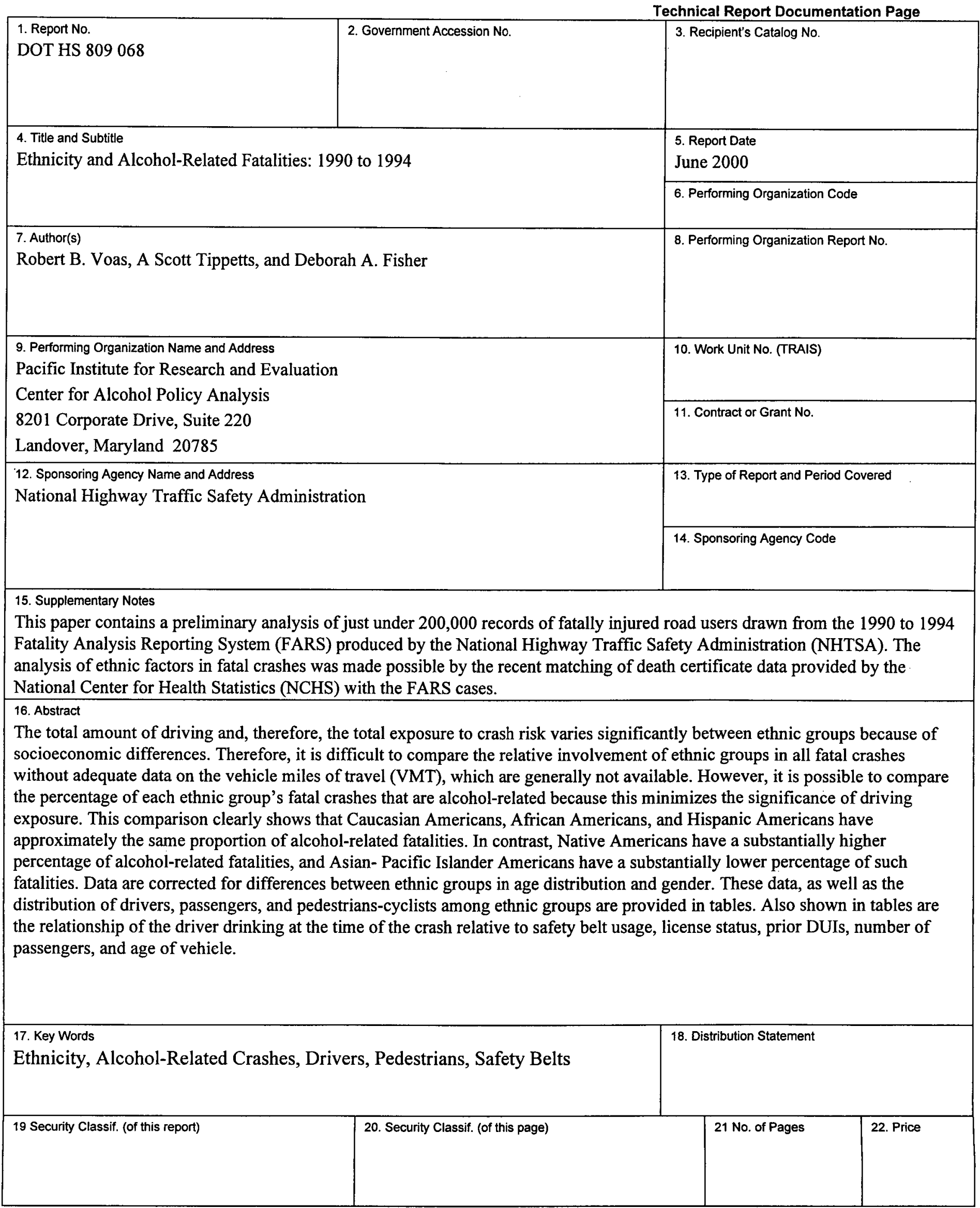




\section{EXECUTIVE SUMMARY}

Until recently, data on the ethnicity of road users killed in motor vehicle crashes have not been available in the Fatality Analysis Reporting System (FARS). An agreement between the National Highway Traffic Safety Administration and the National Center for Health Statistics (NCHS) has made possible the matching of FARS records on fatally injured road users with death certificate data from the NCHS files to obtain race and ethnicity information. This report covers 199,316 fatally injured highway users during the period from 1990 to 1994, which is the latest available data.

This report covers road users (drivers, passengers, pedestrians, and cyclists) who died in a crash within the 50 states and the District of Columbia-no information on ethnicity is available for surviving road users. The fatally injured road users include citizens, residents, and visitors to the United States. The nine ethnic groups covered in this report are Caucasian Americans, African Americans, Native Americans, Asian-Pacific Islander Americans, Mexican Americans, Puerto Rican Americans, Cuban Americans, Central and South Americans, and other unknown Hispanic Americans. ${ }^{1}$

The analysis is based either on the BAC of the road user or on the involvement in an alcohol-related crash. This is defined as a crash in which someone died and where at least one active road user involved had a BAC >.00. An "active" road user is one who could have caused the crash. Passengers are not considered because they very rarely "cause" a crash.

The analyses used the percentage of all fatalities that are alcohol-related to facilitate cross-ethnic comparisons. This minimizes the effect of differences in numbers in each ethnic group and the differences in mileage driven between ethnic groups.

\section{Findings}

- Many features of the drinking driver problem are similar across ethnic groups. Men are more likely than women to be driving at the time of a fatal crash, and men are more likely than women to have been drinking at the time of a fatal alcohol-related crash. The percentage of fatal crashes that were alcohol-related declined for most ethnic groups between 1990 and 1994. Drivers and passengers killed in fatal crashes who had been drinking were least likely to have been wearing safety belts.

- Approximately one in seven road users killed in an alcohol-related crash had not been drinking. Drivers in their 20s and 30s have the highest rate of involvement in alcohol-related crashes.

- Pedestrians who are fatally injured are more likely to be drinking than are drivers. Well over one-half of all pedestrian fatalities for persons ages 16 to 60 are alcohol related. About one in four pedestrian deaths in the 6- to 15-age group are alcohol related.

- There are some features of the drinking driver problem that vary between ethnic groups. Asian-Pacific Islander Americans have distinctly lower rates of alcoholrelated fatalities, and this lower alcohol-related rate for Asian-Pacific Islander

\footnotetext{
${ }^{1}$ The use of the term "American" does not imply U.S. citizenship. The citizenship status of fatally injured road users in the FARS is unknown. Most are U.S. citizens, but the file includes all those killed in the United States some of whom may be foreign visitors, permanent visitors and illegal aliens.
} 
Americans is true for all types of road users: drivers, passengers, pedestrians, and cyclists. Asian-Pacific Islander Americans also have the highest rate of safety belt use by drivers killed in fatal crashes.

- African Americans generally have the same rate of alcohol involvement for drivers and passengers as Caucasian Americans but have a slightly higher rate for pedestrians and cyclists. In age groups above 40, African American drivers and pedestrians tend to have higher percentages of alcohol-related fatalities than Caucasian Americans. Fatally injured African Americans are less likely to be belted at the time of the crash than are Caucasian Americans.

- Among Hispanics, Cuban Americans stand out for their low percentage of alcoholrelated driver, passenger, and pedestrian fatalities. Cuban American fatally injured passengers are more likely than any other ethnic group to have been using restraints at the time of the crash. Next to Native Americans, Mexican Americans have the highest alcohol-related fatality rates among all four types of road users: drivers, passengers, pedestrians, and cyclists. This is true for both men and women.

- Native Americans have the highest percentage of alcohol-involved driver, passenger, and pedestrian fatalities of any ethnic group. Three out of four drivers and eight out of ten pedestrian fatalities occur in alcohol-related crashes. Fatally injured Native American drivers and passengers have the lowest safety belt usage rates of any ethnic group. 


\section{TABLE OF CONTENTS}

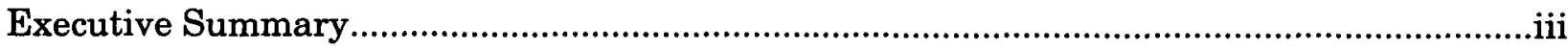

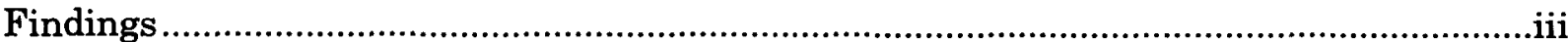

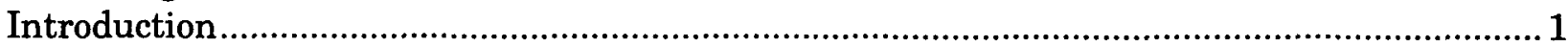

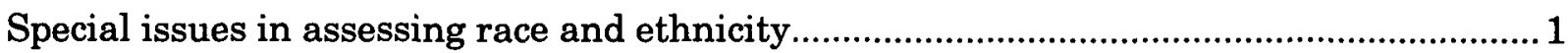

Motor vehicle crash involvement .......................................................................................... 2

Issues in measuring alcohol involvement in crashes .........................................................5

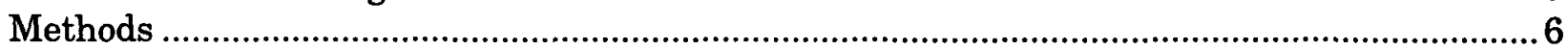

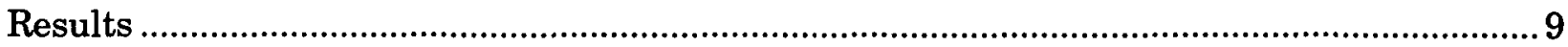

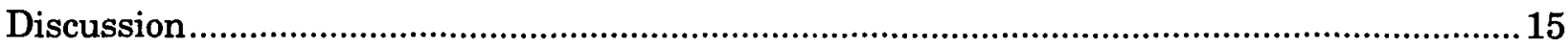

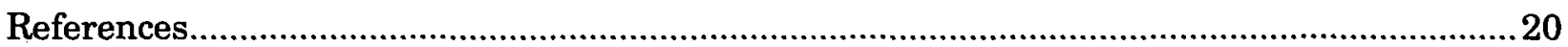

\section{TABLes}

Table 1. Motor vehicle crashes as a cause of death .................................................................. 3

Table 2. Variations in age and gender between ethnic groups: All fatally injured road users, 1990 to 1994 FARS

Table 3. Variations between ethnic groups in role in fatal crash: All fatally-injured road

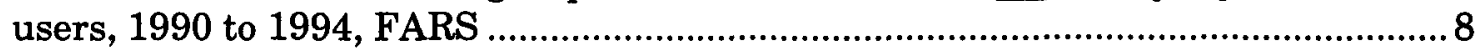

Table 4. Alcohol- and nonalcohol-related fatalities by ethnic group from 1990 to 1994 . Data weighted for age differences.........................................................................................16

Table 5. Alcohol- and non-alcohol-related fatalities by gender and role in crash weighted for age differences between ethnic groups ........................................................................... 17

Table 6. Alcohol- and non-alcohol-related fatally injured drivers by age group. Weighted for gender differences between age groups.

Table 7. Safety belt usage by alcohol- and non-alcohol-related fatally injured vehicle occupants (FARS 1990 to 1995). Data weighted for age and gender.

\section{FIGURES}

Figure 1. Number of alcohol-related fatalities by ethnic group, FARS: 1990 to 1994 ............10

Figure 2. Alcohol-related fatalities by ethnic group (FARS: 1990 to 1994)...........................11

Figure 3. Alcohol-related fatalities by ethnic groups from 1990 to 1994 (FARS) ...................11

Figure 4. Alcohol-related driver fatalities by gender and ethnicity (FARS: 1990 to 1994)....12

Figure 5. Pedestrian fatalities by drinking status of fatally injured pedestrians (FARS: 1990 to 1994) .............................................................................................13

Figure 6. Fatally injured drivers in alcohol-related crashes who had previous alcohol-related driving offenses on their records (FARS: 1990 to 1994)....

Figure 7. Safety belt usage by fatally injured drivers with zero BACs and positive BACs at the time of the crash (FARS: 1990 to 1994). 


\section{INTRODUCTION}

With approximately 183 million licensed drivers nationwide, Americans drive more than 2.5 trillion miles annually (Federal Highway Administration, 1998, online at www.fhwa.dot.gov). The benefits of increased mobility and convenience associated with extensive automobile use have a cost to society in terms of deaths, injuries, and property damage associated with motor vehicle crashes (MVCs). In 1994, motor vehicle traffic crashes were the ninth leading cause of death in the United States, accounting for 41,507 deaths and an age-adjusted death rate of 15.7 per 100,000 population. Among accidental causes of death, MVCs were ranked first, followed by falls, poisoning, suffocation, and fires and flames (NHTSA, 1998). Crashes that result in nonfatal injuries can cause pain, suffering, and potential disability for victims.

Although the harm associated with MVCs touches all segments of society, public health and safety experts have become increasingly concerned about their risks among racial and ethnic minority groups. This concern stems from several sources. First, public health surveillance systems, which systematically collect and analyze data on the prevalence and causes of health conditions in the population, indicate that minorities often bear a disproportionate share of morbidity and mortality. For example, Native American and young African American males are overrepresented in interpersonal violence-related injuries and fatalities (Sugarman \& Grossman, 1996; Wallace, Sleet, \& James, 1997; Castro, Hammond, John, Wyatt, \& Yung, 1995).

Additionally, changing demographic patterns suggest that the involvement of certain population subgroups in MVCs will increase in the near future. For instance, age-related trends in the percentage of deaths from MVCs tend to be similar for Hispanic Americans and nonHispanic Caucasian Americans, with peaks in the 15 to 24 and 25 to 44 age groups (Sainz \& Saito, 1996). Several factors contribute to the increased risk of MVC-related deaths among adolescents and young adults including less experience driving, higher rates of drinking and driving, and lower rates of safety belt use. Because the Hispanic American population will increase dramatically in the next few decades and is younger than the non-Hispanic American population, a greater number of Hispanic Americans will enter those age groups most at risk for MVC-related fatalities.

\section{Special issues in assessing race and ethnicity}

Despite the potential benefits of efforts to identify patterns of health practices and outcomes among population subgroups, a number of problems exist with focusing on racial and ethnic identity. Some of these challenges are conceptual in nature. There is no consensus regarding the concept of race (i.e., whether it reflects biological characteristics, ancestry, geographic origins, or sociocultural group membership). Distinctions between race and ethnicity and between specific racial and ethnic identifiers (e.g., Caucasian American, Hispanic American) are not universally understood or accepted. Ambiguity regarding the criteria of group membership results in "fuzzy" group boundaries rather than exhaustive, and mutually exclusive, racial and ethnic categories (Hahn \& Stroup, 1994).

Recently, philosophical and ethical concerns have caused some scholars, scientists, and other users of public health and census data to question the purpose and value of assessing race. Some have suggested abandoning racial classifications claiming that they are outdated, arbitrary, ambiguous, and racist (Fullilove, 1998; McKenney \& Cresce, 1993). Others have 
proposed new terminology be used in describing and comparing population subgroups in scientific research (Bhopal \& Donaldson, 1998).

In addition to the conceptual and philosophical considerations are the more practical issues associated with assessing race and ethnicity. Lack of reliability in self-reports of race and ethnicity can occur for a variety of reasons including a respondent's lack of understanding of the intent or wording of items assessing racial and ethnic identity, problems with classifying those of mixed race, and shifts over time in an individual's self-perceived group identity (Hahn \& Stroup, 1994; McKenney \& Bennett, 1994). Inconsistencies across data sets that collect information on race and ethnicity occur because of the use of different methods of data collection (e.g., self-identification on survey, interviewers' observations, reports by next of kin), different item formats and content (e.g., using two items to assess race and ethnicity separately or using a combined item), and different classification schemes (McKenney \& Bennett, 1994).

Popular categories of race and ethnicity are not scientifically derived; instead, they represent individuals' self-perceived membership in a population defined by multiple, diverse features (Hahn \& Stroup, 1994). These racial and ethnic identifications, however, have been and continue to be important determinants of health status and access to societal resources. Thus, in spite of the considerable challenges posed by efforts to assess race and ethnicity, many practitioners and researchers continue to believe that these data are useful to public health surveillance and efforts to reduce preventable excesses in poor health among population subgroups. With careful attention to the complex and changing issues involved in collecting information on race and ethnicity, the tracking of health and safety issues among population subgroups can enhance our knowledge about the occurrence and causes of problems and inform efforts to develop effective and culturally sensitive interventions.

\section{Motor vehicle crash involvement}

The issue of whether racial and ethnic minorities are overrepresented in MVCs is most often assessed with fatality data. Annual mortality data for the nation are compiled by the National Center for Health Statistics (NCHS) from a census of death records (certificates) submitted from the states and territories. Causes of death are classified according to internal bodily diseases and disorders and external factors causing injury (including motor vehicle crashes) using the World Health Organization's International Classification of Diseases (ICD).

Death rates provide a measure of the risk of dying from various causes based on the incidence of fatalities within population subgroups. Expressed in terms of a common metric such as the number of deaths per 100,000 population, they are calculated by dividing the total number of fatalities from a stated cause by a subgroup's population and then multiplying by 100,000 . Age-adjusted death rates show what the level of mortality would be if the age composition of the population were held constant. Age-adjusted death rates are better indicators for comparisons of mortality between subgroups of the population with different age distributions. The ratio of two groups' death rates is one way to assess the relative risk of death due to a particular cause for members of one population compared to another.

In addition to death rates, the contribution of motor vehicle crashes to mortality can also be assessed within population subgroups in terms of what proportion of total deaths are attributed to them and their rank order among causes of death. Table 1 provides age-adjusted death rates, percentage of total deaths, and rank order for motor vehicle crashes for all ages, by ethnicity and gender, based on NHTSA's analyses using NCHS mortality data for 1994 (NHTSA, 1998). 
TABLE 1. MOTOR VEHICLE CRASHES AS A CAUSE OF DEATH

\begin{tabular}{|c|c|c|c|}
\hline & $\begin{array}{c}\text { Age-adjusted death } \\
\text { rates }\end{array}$ & $\begin{array}{c}\text { Percentage of total } \\
\text { deaths }\end{array}$ & Rank order \\
\hline \multicolumn{4}{|c|}{ Caucasian American ${ }^{\star}$} \\
\hline Males & 21.7 & 2.4 & 7 \\
\hline Females & 9.8 & 1.2 & 10 \\
\hline \multicolumn{4}{|c|}{ African American } \\
\hline Males & 24.3 & 2.4 & 10 \\
\hline Females & 9.4 & 1.3 & 15 \\
\hline \multicolumn{4}{|c|}{ Native American } \\
\hline Males & 42.6 & 4.7 & 3 \\
\hline Females & 31.5 & 4.9 & 5 \\
\hline \multicolumn{4}{|c|}{$\begin{array}{l}\text { Asian-Pacific Islander } \\
\text { Americans }\end{array}$} \\
\hline Males & 12.7 & 3.5 & 5 \\
\hline Females & 7.6 & 3.0 & 6 \\
\hline \multicolumn{4}{|c|}{ Hispanic American } \\
\hline Males & 24.2 & 5.7 & 5 \\
\hline Females & 8.1 & 2.8 & 6 \\
\hline
\end{tabular}

* Throughout this report the term American does not imply u.s. citizenship. the citizenship status of the fatally injured road users is unknown.

Across all racial and ethnic groups, more males die from MVCs than females. The risk of death from traffic crashes for males was 2.2 times the female risk, with age-adjusted death rates of 21.8 and 9.7 , respectively. In recent years, males have accounted for $67 \%$ to $70 \%$ of all deaths due to MVCs although they only represent approximately $49 \%$ of the U.S. population.

Traffic crashes are a leading cause of death for both children and adults through the fourth decade of life. Pooled across gender, traffic crashes were among the top four leading causes of death for all ages from 1 to 41 . Further, traffic crashes were the number one cause of all deaths (26\%) occurring from age 6 to age 27. The risk of traffic deaths for this age group was 18.1 deaths per 100,000 population, which is almost $14 \%$ as great as the average risk of traffic deaths for persons of all ages (18.1 versus 15.9).

In addition to gender and age-related trends, differences between racial and ethnic groups exist for traffic crashes as a cause of death. Compared to Caucasian Americans in 1994, African Americans had a slightly higher age-adjusted death rate from motor vehicle crashes (16.3 versus 15.8 per 100,000 ), whereas the death rate was twice as high for Native Americans (33.0 per 100,000). In contrast, the motor vehicle death rate for Asian- Pacific Islander Americans was about two-thirds the rate for Caucasian Americans at 10.0 per 100,000. As a proportion of total deaths, MVCs accounted for about the same percentage of deaths in Caucasian Americans and African Americans (2.4\% of male deaths, $1.2 \%$ to $1.3 \%$ of female deaths); however, they accounted for higher percentages of deaths among Native Americans, Asian-Pacific Islander Americans, and Hispanic Americans. 
In a recent study using NCHS mortality data and survey data regarding the amount and type of personal travel, both population-based and exposure-based motor vehicle occupant death rates were calculated for Caucasian American, African American and Hispanic American children and adolescents (Baker, Braver, Chen, Pantula, \& Massie, 1998). Among children 5 to 12 years old, race and ethnicity differences per 100,000 persons were negligible; however, death rates per unit of travel differed markedly by race and ethnicity. African American children had the highest exposure-based death rates, both in terms of billion vehicle miles of travel (VMT) (14 deaths, followed by Hispanic Americans at 8 deaths and Caucasian Americans at 5 deaths) and 100 million trips ( 8 deaths, compared to 5 for Hispanic Americans and 4 for Caucasian Americans). Among adolescents 13 to 19 years old, the population-based death rates for Caucasian Americans were almost twice that for African Americans and Hispanic Americans. Rates per billion VMT, however, were 45 for Hispanic Americans, 34 for African Americans, and 30 for Caucasian Americans. Per 100 million trips, rates were highest for Hispanic Americans and slightly lower for African Americans than for Caucasian Americans $(32,24$, and 28 , respectively). Gender had little effect on mileage-based occupant death rates among younger children; however, among adolescents 13 to 19 years old, male rates were substantially higher than female rates per billion VMT. African American and Hispanic American male teenagers had significantly higher occupant death rates per billion VMT (66 and 61, respectively) than either Caucasian American males (37) or female teenagers of any race or ethnicity-rates for females were 14, 25, and 22 for African Americans, Hispanic Americans, and Caucasian Americans, respectively.

Information on motor vehicle crash mortality also comes from state-level cause-of-death studies. For example, Schiff and Becker (1996) examined ethnic differences and trends in motor vehicle fatality rates in New Mexico from 1958 to 1990. They found that, throughout the 33 years, males had higher motor vehicle traffic death rates than females among all ethnic groups. For each ethnic group and both genders, the highest mortality rates were found in the 15 to 19 , 20 to 24 , and 25 to 29 age groups. Death rates peaked in the 1970 s but, by 1990 , had decreased an average 16 deaths per 100,000 among males and 1.5 deaths per 100,000 among females. Over the study period, Native Americans of both genders had two to four times higher ageadjusted mortality rates than non-Hispanic Caucasian Americans. Hispanic American males also had consistently higher motor vehicle death rates than non-Hispanic Caucasian American males. From 1988 to 1990, age-adjusted death rates among males were 115.9 for Native Americans, 50.6 for Hispanic Americans, and 30.6 for non-Hispanic Americans. The corresponding rates among females were 39.0 for Native Americans, 16.4 for Hispanic Americans, and 13.8 for non-Hispanic Caucasian Americans. Motor vehicle fatality rates were not examined among African Americans or other racial or ethnic groups because of the small number of deaths, which accounted for only 3\% of New Mexico's population over the study period.

A study of motor vehicle fatalities in Arizona from 1979 through 1988 (Campos-Outcalt, Prybylski, Watkins, Rothfus, \& Dellapenna, 1997) linked crash data from the FARS with the NCHS Multiple Cause of Death data for Arizona residents to obtain race and residence information on each traffic fatality. Seventy-six percent of FARS records and $80 \%$ of death certificates were matched and provided data for analyses. Each case was classified into Native American and non-Native American categories. Consistent with the New Mexico study, annual age-adjusted death rates were consistently elevated for Native Americans relative to other Arizona residents regardless of gender or urban or rural residence. Among Native Americans, the relative risk was significantly elevated for urban males at 3.0, rural males at 3.1, and urban females at 2.7; the relative risk for rural females at 2.3 was not significantly higher. With 
respect to age, the relative risk for Native American vehicle occupants was elevated for all age groups-ranging from 1.5 to 6.4-although it reached statistical significance only in the 15 to 24,25 to 34 , and 35 to 44 age groups.

Another state-level study used 3 years of crash data (1993-1995) obtained from the Florida Department of Highway Safety and Motor Vehicles to investigate the effects of demographic and roadway factors on traffic crash involvement (Aty \& Radwan, 1998). Consistent with the findings discussed above, data for both resident and nonresident total crash involvement (injury and fatal crashes) showed a higher rate for males than for females at every age group. Additionally, total crash involvement risk was higher for adolescents and young adults. Among racial and ethnic groups, African American drivers had the highest risk of total crash involvement in 1995, with a rate of 4.82 involvement per 100 population, followed by Caucasian Americans at 2.92, and Hispanic Americans with the lowest rate of 2.22. Both African American male and female drivers had the highest risk of crash involvement with rates of 6.11 and 3.70 , respectively.

\section{Issues in measuring alcohol involvement in crashes}

Several measures have been used to examine the phenomenon of alcohol-impaired driving. These measures can be categorized as official statistics (or archival data) and selfreports of impaired driving; within each of these categories, there are direct and indirect measures. In their literature review, Ross, Howard, Ganikos, and Taylor (1991) described the different types of measures and issues associated with using each. This section is a summary of their discussion of measurement issues in impaired driving research.

Official statistics that measure impaired driving directly provide the most reliable and valid assessment of its incidence. The most straightforward direct archival measure uses a roadside survey to collect breath specimens from a representative sample of drivers that are analyzed for Blood Alcohol Concentration (BAC) levels. Another direct archival measure uses the population of persons killed in highway crashes to assess alcohol involvement. The chief source for data on alcohol impairment in fatal crashes comes from the NHTSA's FARS that, since 1975, has collected information on fatal crashes, including alcohol involvement, although alcohol testing is not comprehensive and testing rates vary widely across the states. Because estimates based on testing small numbers of drivers may be biased, NHTSA uses a procedure for developing estimates of impairment that are statistically corrected for testing incompleteness. When linked with death records identifying race (which is not included in the FARS), the detailed crash data from the FARS can be used to examine differences across racial and ethnic groups in impaired driving and other factors related to motor vehicle fatalities.

Other forms of archival data do not measure impaired driving directly; instead, they measure something that is correlated with it and may be used as an index of the problem. These surrogate measures tend to be less valid problem indicators. For example, certain types of traffic crashes are alcohol involved to varying degrees. Whereas fatal crashes involve alcohol about $50 \%$ of the time, weekend single-vehicle nighttime fatal crashes have alcohol involvement rates that can exceed $80 \%$. Although crash-fatality data often include the race of the deceased, fatalities are relatively rare events and numbers may be too small to provide stable estimates, especially among population subgroups. The issue of sample size becomes increasingly problematic as efforts to limit analyses to those kinds of crashes most closely associated with alcohol result in a greatly reduced database. Thus, highly refined indexes are useful for estimating impaired driving only in large populations. 
Other surrogate archival measures include crashes designated as alcohol related based on police judgment (rather than BAC data) and driving-while-intoxicated (DWI) arrest statistics. Police-designated "alcohol-related" crashes may be unreliable if police judgments are erroneous or biased. The weakest of the surrogate archival measures are DWI arrests, which occur in only about one in 500 to 1,000 incidents of impaired driving. Rather than a reflection of the actual incidence of DWI, arrest rates are greatly affected by the resources expended on drunk-driving patrols and apprehensions by police. As with specifying alcohol involvement in crashes, biases in stopping and testing drivers in different population ethnic or racial groups may lead to an overstatement of their DWI rates.

Aside from official statistics, researchers have also used self-reports of behavior obtained from surveys administered to large numbers of individuals. Among self-reports, questions regarding the extent to which respondents have driven after drinking are considered direct measures, and questions regarding alcohol consumption provide surrogate measures. Selfreports of drinking and drinking-and-driving are problematic for several reasons. First, questions are often vague, leaving room for interpretation and confusion (e.g., querying respondents about incidents of impaired driving by asking them how many times they drove when they "had too much to drink"). In addition to the issue of their validity in assessing the behavior of interest, the answers to such survey items can be expected to be strongly affected by the social desirability of possible responses. Underreporting can produce low estimates of the incidence of drinking and impaired driving. For example, Smith and Remington (1989) estimated that DWI occasions were underreported in their survey by about two-thirds. More recently, Robertson (1992) found that self-reports of driving after drinking were poorly correlated with the percentage of illegal BACs in fatally injured drivers among 19 states $\left(R^{2}=0.20\right)$. Differential levels of underreporting can cause biases in comparisons among population ethnic and racial groups.

\section{METHODS}

The FARS is perhaps the world's best record system for fatal crashes. It contains considerable detail about roadways, vehicles, road users, weather, time of day, and other factors relating to each fatal crash (defined as a crash causing a death within 30 days of the event). Before 1987, because ethnicity had not been one of the data elements in the system, the FARS data, maintained by the NHTSA, could not be used to study the differences in crash involvement among members of the various ethnic and racial groups. Over the past decade, this has changed. The NHTSA, working with the NCHS, has matched the records of road users who are fatally injured in crashes with their death certificate information in the NCHS file called the Hyde Cause of Death (HCOD) file.

This is a continuing effort. However, currently race and ethnicity data are available only in the FARS file for the years 1987-89 and 1990 through 1994. The file for 1990-1994 provides records for just fewer than 200,000 highway fatalities that contain information about the race or ethnicity of a fatally injured person. This designation is taken from funeral directors' reports but may also be derived from other sources such as coroners' records. Thus, the ethnic designation in individual cases may be in error. Nevertheless, these designations appear to be sufficiently accurate for a general analysis of the differences between ethnic groups' involvement of drivers, passengers, and pedestrians-cyclists in alcohol-related crashes. The nine ethnic groups covered in this report are Caucasian Americans, African Americans, Native Americans, Asian-Pacific Islander Americans, Mexican Americans, Puerto Rican Americans, Cuban Americans, Central and South Americans, and other unknown Hispanic Americans. 
Mothers Against Drunk Driving (MADD) and NHTSA used this report to support their diversity conference on traffic safety in February 1999.

This study covered 199,316 fatally injured road users in crashes occurring in the United States between January 1, 1990, and December 31, 1994, the most recent 5 years for which there are FARS ethnicity data. This sample included only fatally injured individuals because they were the only road users for whom ethnicity data were available. As a result, the estimated percentages of totally involved road users involved in alcohol-related crashes provided in this report are slightly higher than for other reports from the FARS file that include both surviving and fatally injured participants because a smaller percentage of surviving drivers have positive BACs. For each participant in a fatal crash recorded in the FARS, either the actual BAC collected by the coroner at the time of death or an estimated crash BAC based on an imputation system developed by the NHTSA (Klein, 1986) is provided. The Klein imputation procedure classifies $\mathrm{BAC}$ into three categories: $\mathrm{BAC}=0, \mathrm{BAC}=.01-.09$, and $\mathrm{BAC}=.10+$. The present study used the traditional "alcohol-related" term for the second two categories. A similar study could be done that limited the analysis to the $\mathrm{BAC}=10+$ category.

This study reports on this information in two forms. The first one is whether the fatality occurred in an alcohol-related crash, which are those crashes having a driver, a pedestrian, or a cyclist (the three types of active road users) with a positive BAC. Passengers are not considered "active" participants as they are assumed not to have contributed to crash causation. That definition of an alcohol-related crash provides that drinking road users surviving the crash and, therefore, not among the 199,316 cases analyzed, can contribute to the designation of a crash as alcohol-related.

A second method of reporting is based on whether the fatally injured individual had an actual or estimated positive BAC. This is useful because the difference between the number of road users fatally injured in alcohol-related crashes and the percentage of those who were drinking provides an estimate of the number of "innocent" nondrinking road users killed in alcohol-related crashes. Very few passengers were tested for BAC; therefore, for this study they were assigned the drinking status of the driver of the vehicle in which they were riding.

Fatal crashes are caused by many factors. Among these are the number of miles each person drives, the types of vehicles each one drives, the roadways upon which each one drives, and the days of the week and times of night in which each one drives. Because these factors are likely to vary across ethnic groups, it is difficult to compare the absolute number of alcoholrelated crashes. To provide a reasonable basis for comparing the relative alcohol involvement of fatalities across ethnic groups, the percentages of all fatal crashes that are alcohol-related $(\mathrm{BAC}>.00)$ is used, rather than the absolute number. Consequently, factors such as the economy, miles driven, type of vehicle, and type of roadway will have less affect on the comparison of different ethnic groups because each group's alcohol-related crashes are compared against other non-alcohol-related crashes for the same group. Using this percentage does not correct perfectly for all such influences, but it is the best measure for producing a reasonable basis for comparison of ethnic groups or of demographic factors (such as age and gender) within ethnic groups. 
Ethnicity and Alcohol-Related Fatalities: 1990 to 1994

TABLE 2. VARIATIONS IN AGE AND GENDER BETWEEN ETHNIC GROUPS: ALL FATALLY INJURED ROAD USERS, 1990 TO 1994 FARS

\begin{tabular}{|c|c|c|c|c|c|c|c|c|c|c|}
\hline & \multicolumn{2}{|c|}{$0-15$ years } & \multicolumn{2}{|c|}{$16-20$ years } & \multicolumn{2}{|c|}{$21-39$ years } & \multicolumn{2}{|c|}{ 40-59 years } & \multicolumn{2}{|c|}{$60+$ years } \\
\hline & male & female & male & female & male & female & male & female & Male & female \\
\hline $\begin{array}{l}\text { Percent of Category that were } \\
\text { Alcohol Involved (for Caucasians) }\end{array}$ & 22.1 & 23.4 & 47.1 & 35.2 & 67.1 & 50.7 & 50.8 & 32.1 & 22.2 & 14.1 \\
\hline Caucasian Americans & 4.0 & 2.8 & 10.2 & 4.5 & 28.0 & 10.0 & 12.6 & 6.0 & 12.2 & 9.7 \\
\hline African Americans & 7.6 & 4.9 & 8.8 & 2.8 & 31.7 & 10.6 & 14.6 & 5.8 & 8.7 & 4.5 \\
\hline Native Americans & 4.9 & 4.1 & 10.2 & 4.5 & 35.3 & 13.7 & 13.8 & 5.5 & 4.9 & 3.2 \\
\hline $\begin{array}{l}\text { Asian-Pacific Islander } \\
\text { Americans }\end{array}$ & 6.2 & 3.7 & 8.7 & 3.7 & 24.7 & 12.6 & 11.2 & 9.9 & 10.1 & 9.4 \\
\hline Mexican Americans & 6.9 & 4.3 & 13.1 & 3.2 & 41.2 & 9.0 & 11.1 & 3.9 & 4.6 & 2.7 \\
\hline Puerto Rican Americans & 7.8 & 4.5 & 10.9 & 3.1 & 30.8 & 8.8 & 17.3 & 5.7 & 7.0 & 4.1 \\
\hline Cuban Americans & 4.7 & 1.1 & 6.0 & 1.8 & 23.7 & 5.4 & 16.3 & 7.0 & 22.0 & 12.1 \\
\hline Central-South Americans & 3.8 & 3.2 & 10.0 & 2.1 & 46.0 & 10.4 & 12.1 & 6.2 & 2.5 & 3.8 \\
\hline
\end{tabular}

TABLE 3. VARIATIONS BETWEEN ETHNIC GROUPS IN ROLE IN FATAL CRASH: ALL FATALLY-INJURED ROAD USERS, 1990 TO 1994, FARS

\begin{tabular}{|c|c|c|c|c|}
\hline & \multicolumn{3}{|c|}{ Role } \\
\hline & & Drivers & passengers & ped/cyclist \\
\hline \multicolumn{2}{|c|}{$\begin{array}{l}\text { Percentage of Category that were } \\
\text { Alcohol Involved (for Caucasians) }\end{array}$} & 46.2 & 39.6 & 43.6 \\
\hline \multirow[t]{8}{*}{$\begin{array}{l}\text { Distribution } \\
\text { of Ethnic } \\
\text { Group's } \\
\text { Fatalities } \\
\text { Across } \\
\text { Strata } \\
\text { (\% of row) } \\
\end{array}$} & Caucasian Americans & 62.2 & 24.7 & 13.1 \\
\hline & African Americans & 47.5 & 27.4 & 25.1 \\
\hline & Native Americans & 44.0 & 33.3 & 22.7 \\
\hline & $\begin{array}{l}\text { Asian-Pacific Islander } \\
\text { Americans }\end{array}$ & 42.2 & 36.0 & 21.8 \\
\hline & Mexican Americans & 43.7 & 33.7 & 22.6 \\
\hline & Puerto Rican Americans & 42.1 & 26.3 & 31.6 \\
\hline & Cuban Americans & 44.4 & 25.7 & 29.9 \\
\hline & Central-South Americans & 39.9 & 31.1 & 29.0 \\
\hline
\end{tabular}

Although using the percentage of alcohol-related crashes reduces the potential impact of roadway, vehicle, and economic factors, it does not fully correct for the age and gender differences between ethnic groups in the extent to which they are involved in fatal crashes. A standard procedure in comparing ethnic groups' involvement in mortality studies is to use age-weighted rates. Typically, ethnicity data from the U.S. Census are used to determine the numbers in each age group. This provides a rate estimate based on all members of the population whether they are exposed to the disease entity or not. There is significant variation within ethnic groups in exposure to highway crashes since many individuals may have no access to vehicles. The base age and gender statistics based on all fatalities in the FARS appeared to be a more appropriate basis for weighting the data than to use population estimates from the census. The percentage of each ethnic group by age group and gender among the 199,316 cases analyzed in the current study is shown in Table 2. There are some substantial differences in the age representation for some ethnic 
groups. For example, in the high-risk age group from 21 to $39,67 \%$ of the Caucasian American male drivers are fatally injured in alcohol-related crashes. The percentage of Caucasian American drivers in this category is $28 \%$ compared to $41 \%$ for Mexican American drivers and $46 \%$ for Central and South American fatalities. Thus, apparent differences between ethnic groups could be produced simply because of differences in the age and gender distribution of the individuals fatally injured within ethnic groups. To remove these biases, data for the non-Caucasian American ethnic groups were weighted to conform with the Caucasian American percentage in each age and gender grouping. There were also substantial differences between ethnic groups in the percentage of all fatalities who were drivers, passengers, or pedestrians-cyclists as shown in Table 3 . Note that $62 \%$ of the Caucasian American fatalities were drivers compared to less than $50 \%$ for all other ethnic groups. The results reported in this study are not weighted to account for these differences in role. Rather, the results are reported separately for each type of road user. Only where total fatalities for each ethnic group are considered does this difference between groups in the percentages of fatalities falling into each role need to kept in mind.

The number of cases within particular ethnic groups varies slightly among the tables because some cases having missing values for the variable being compared. Since those cases cannot be categorized due to the missing values, they are not counted in that particular table.

\section{RESULTS}

Figure 1 presents a picture of the relative number of alcohol-related fatalities by ethnic group. From 1990 to 1994, 72\% of the alcohol-related fatalities involved Caucasian Americans. This is because they are the largest population group and drive more vehicle miles each year than any other ethnic group. Thus, the numeric differences shown in Figure 1 are related not only to the size of the population, but also to the amount of driving. They illustrate why it is important to report on alcohol-related crashes in a form that is not strongly influenced by the total population or the number of vehicle miles driven. Using the percentage of all fatalities that are alcohol-related permits a comparison of these quite differently sized groups.

The large proportion of Caucasian Americans in the figure also illustrates the importance of adding ethnicity to the FARS data sets. Without that information, the characteristics of Caucasian Americans involved in alcohol-related fatal crashes would overwhelm the contribution from other ethnic groups. Because differences among other ethnic groups are obscured by this large group, the information drawn from previous studies using FARS is principally applicable to Caucasian Americans. Only from this point (1990) forward can the FARS file be used to study the individual ethnic characteristics of the alcohol and highway safety problem.

Table 4 provides information on total alcohol-related fatalities for the 5 years covered by this study for nine ethnic groups. These data have been weighted for both age and gender to match the majority in the Caucasian American ethnic group. However, they have not been corrected for differences between the proportion of fatalities that are drivers, passengers, and pedestrians. Therefore, these differences may contribute to some of the contrast between ethnic groups across the 5 years. Within each cell, the top line lists the fatalities in crashes where no active road user had been drinking. The second line lists the 


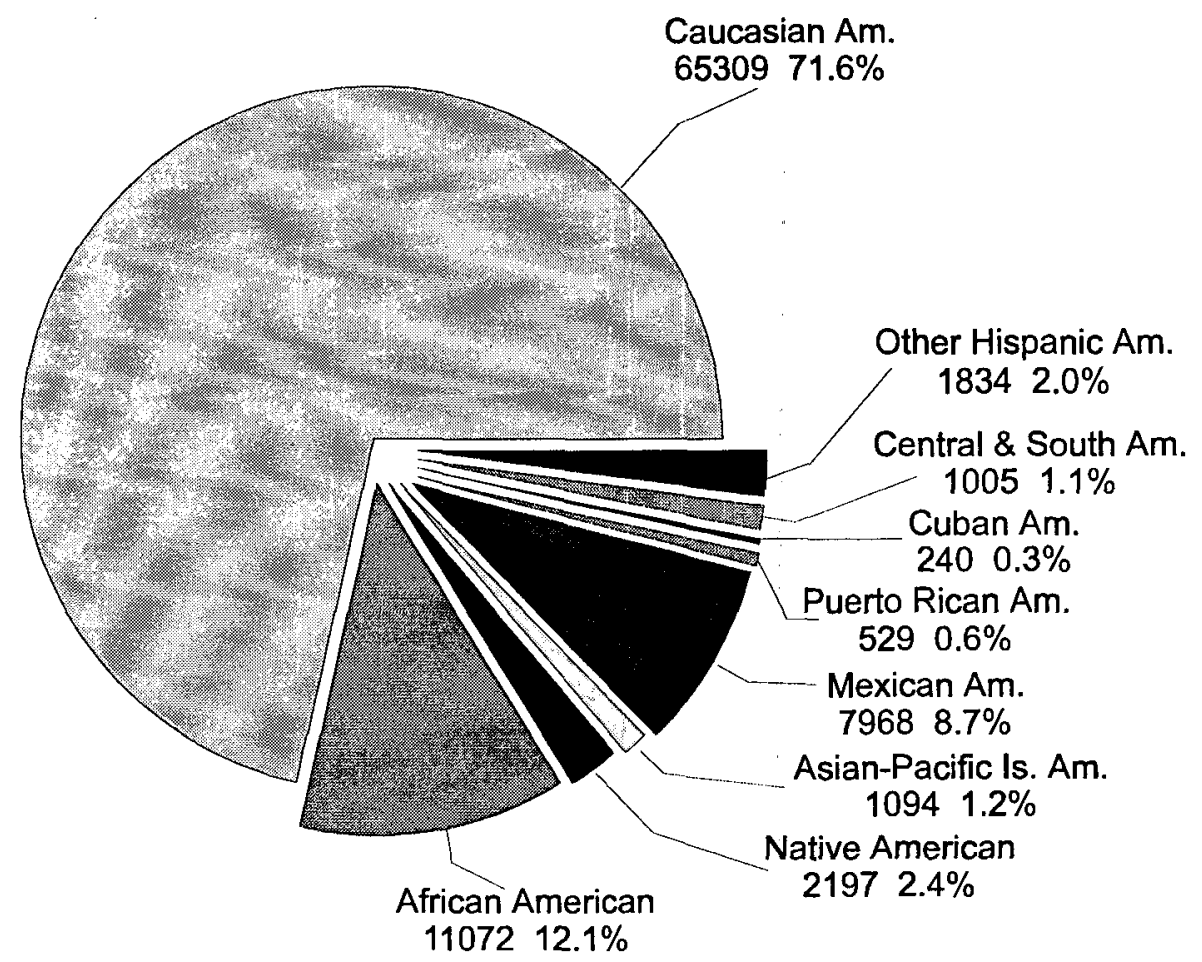

FIGURE 1. NUMBER OF ALCOHOL-RELATED FATALITIES BY ETHNIC GROUP, FARS: 1990 TO 1994

fatally injured persons who were killed in an alcohol-related crash but had not been drinking. The third line gives the number of individuals fatally injured in alcohol-related crashes who had been drinking. The fourth line (shaded) provides the percentage of all fatalities for those who died in alcohol-related crashes whether or not they personally had been drinking. The fifth and bottom line (shaded) provides the percentage of all fatalities for those who had been drinking.

The right-hand column provides summary data for the 5 years from 1990 to 1994 . Note that the proportion of fatalities in alcohol-related crashes is approximately the same for Caucasian Americans and African Americans (44.2\% and 45.2\%). The Hispanic groups range somewhat above (Mexican Americans: 54.6\%) and below (Cuban Americans: 36.6\%) this level in the proportion of alcohol-related fatalities. Standing out from these groups are Native Americans with a substantially higher alcohol-related fatality rate of $68.1 \%$ and Asian-Pacific Islanders with an alcohol-related fatality rate of $28.2 \%$. These are shown in Figure 2. 


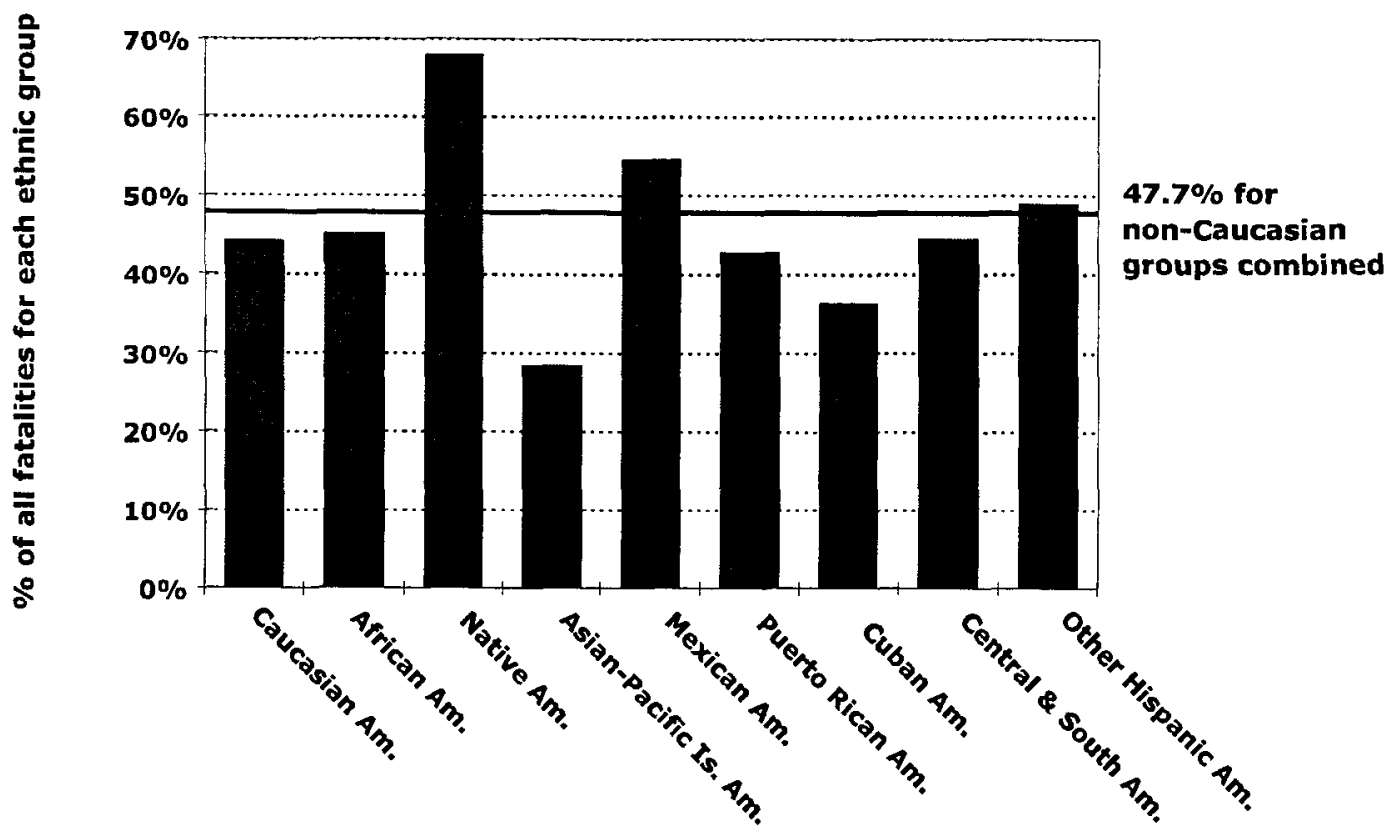

FiguRE 2. ALCOHOL-RELATED FATALITIES BY ETHNIC GROUP

An examination of the percentage of fatalities in alcohol-related crashes across the 5 years (as shown in Table 4) indicates that, during that period, the percentage of all fatalities stemming from alcohol-related crashes was reduced for all ethnic groups. The proportionate reduction was greatest for the Asian-Pacific Islander Americans and smallest for the Native Americans. The reduction over the 5 years for Caucasians and African Americans was essentially the same. Cuban Americans also demonstrated a substantial reduction; however, the number in this ethnic group is too small to give this much significance. These trends (for the largest ethnic groups only) are displayed in Figure 3.

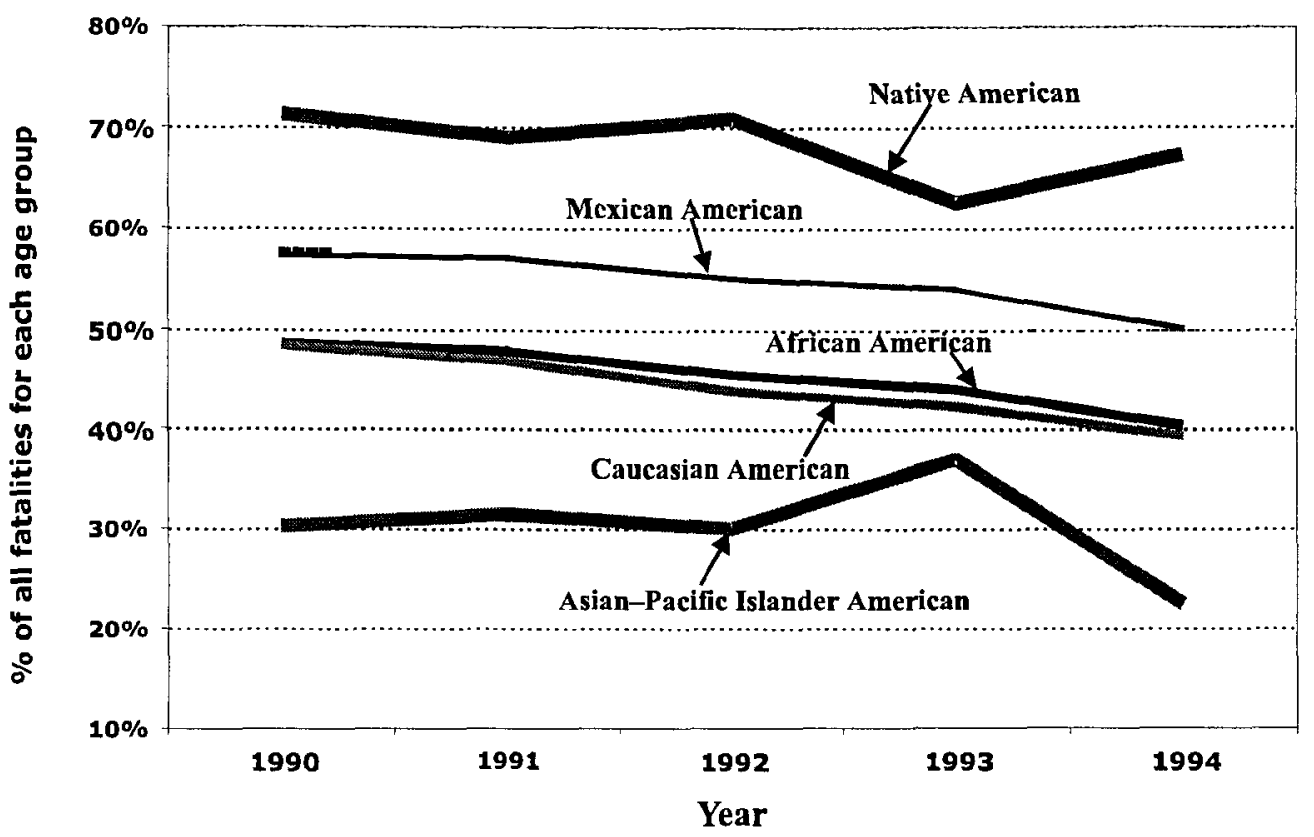

FIGURE 3. ALCOHOL-RELATED FATALITIES BY ETHNIC GROUP FROM 1990 TO 1994 (FARS)

Table 5 presents data on fatalities by role in the crash for males and females. These data are weighted to compensate for age differences between ethnic groups. A higher proportion 
of males than females is involved in alcohol-related crashes whether their involvement was as a driver, passenger, or pedestrian/cyclist. Note that the pedestrian/cyclist group includes pedalcyclists but not motorcyclists who are included in the driver group. Gender differences in alcohol-involvement (for drivers only) are shown in Figure 4. There are, however, significant differences between ethnic groups in the pattern of alcohol-related fatalities across the three crash roles. For Caucasian Americans, the percentage of alcohol involvement is essentially the same whether the participant was a driver, passenger, or pedestrian/cyclist. For African Americans, however, the proportion of pedestrians/cyclists killed in alcohol-related crashes is greater than the percentage of drivers or passengers killed in such crashes. Native Americans show the same pattern. Asian-Pacific Islander Americans, on the other hand, show the opposite pattern. A smaller proportion of their pedestrians die in alcohol-related crash fatalities than do their drivers.

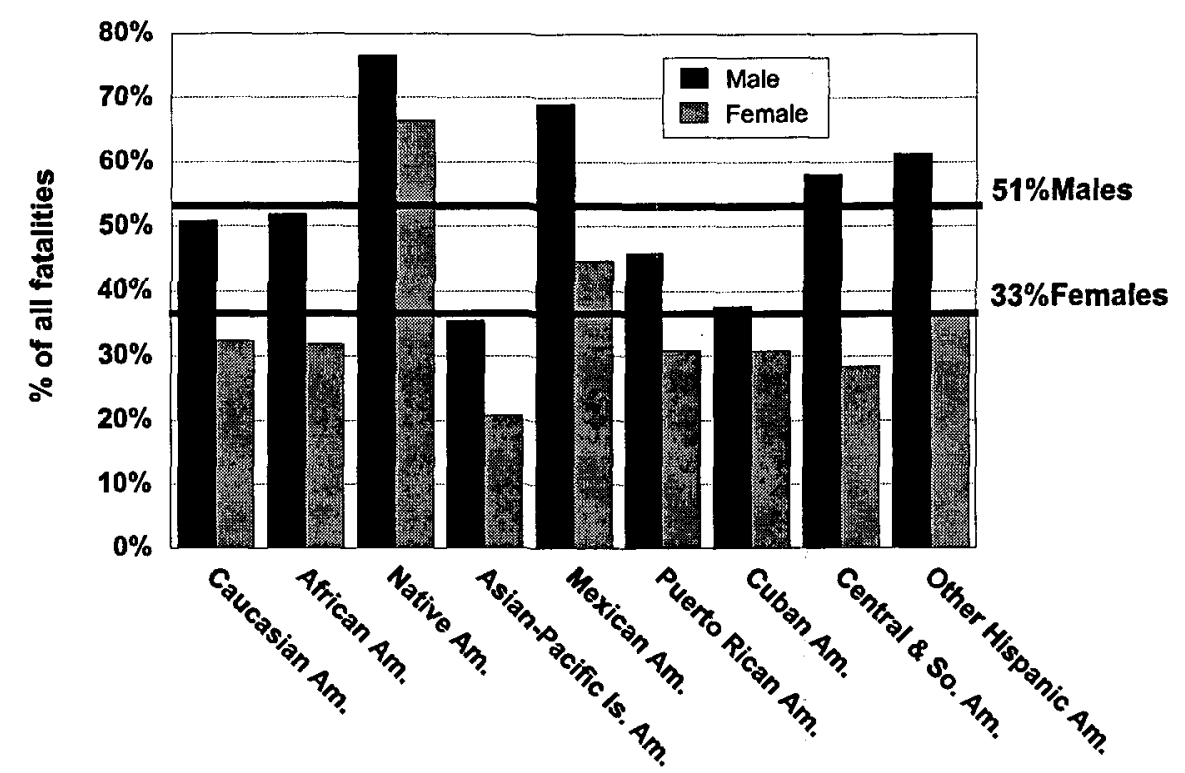

FIGURE 4. ALCOHOL-RELATED DRIVER FATALITIES BY GENDER AND ETHNICITY

(FARS: 1990 TO 1994)

Of particular interest within this table is the role of alcohol for cases in which a pedestrian was killed. When alcohol was involved in these crashes, the pedestrian was generally two to three times as likely to be alcohol-positive than was the driver for all groups, with the exception of Asian-Pacific Islander Americans, for whom alcohol-involvement was roughly equal between driver and the pedestrian-victim (displayed in Figure 5). The largest difference in alcohol-involvement between drivers and pedestrians in these crashes is seen in the Native American group, for whom ten times as many pedestrians were alcohol-positive as drivers.

The involvement of alcohol by the killed drivers themselves (the "Person Alcohol" row in the first two "Drivers" columns of Table 5) is lowest for Asian-Pacific Islanders and Cuban Americans, of whom $26 \%$ and $30 \%$, respectively, were alcohol positive (pooled across gender). Native American drivers and Mexican American drivers were highest, at $64 \%$ and $53 \%$ respectively. As can be seen in Figure 6, these patterns of alcohol-positive drivers correspond to the similar pattern of rates of previous DUIs among all drivers killed in alcohol-related crashes. Overall, roughly $10 \%$ of these killed drivers (who may or may not have been the alcohol-positive party in the particular crash that killed them) had a prior DUI or similar alcohol-related offense on their driver record. Cuban American and Asian-Pacific Islander American drivers killed in alcohol-related crashes had the lowest rates of prior DUIs, only $2 \%$ 
and $4 \%$ respectively, whereas $15 \%$ of Native American drivers and $13 \%$ of Mexican American drivers who were killed in an alcohol-related crash had one or more prior DUIs.

FiguRE 5. PEDESTRIAN FATALITIES BY DRINKING STATUS OF FATALLY INJURED PEDESTRIANS

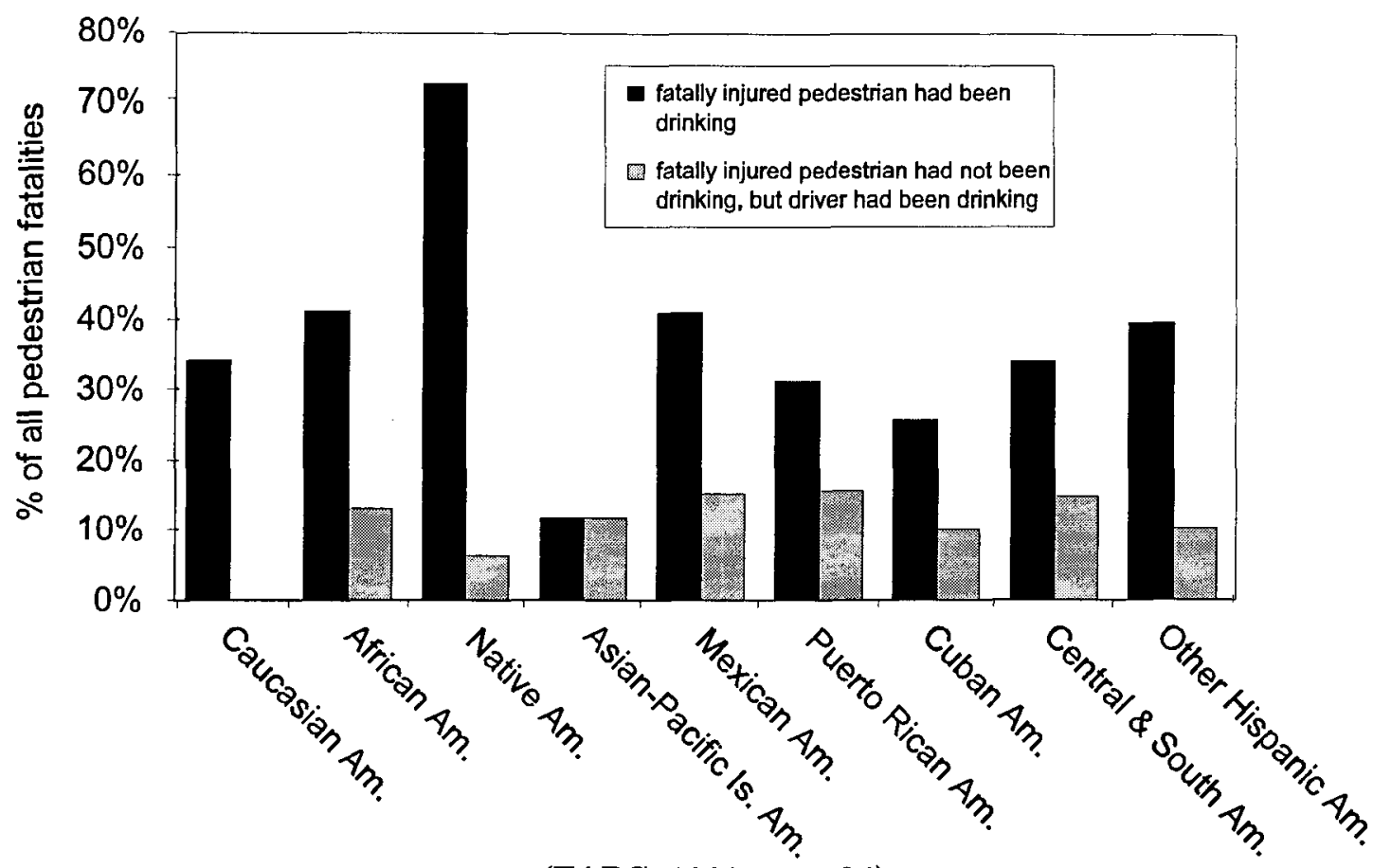

(FARS: 1990 TO 1994)

Table 6 shows the proportion of fatalities in alcohol-related crashes by age intervals. Consistent with other research, the highest proportion of alcohol-related, driver fatalities occurred in the age groups between 21 and 40, with lower rates for those drivers under age 21 and over age 40 . Although the numbers are small and, therefore, subject to considerable variation, the fact that for the age group from 21 to 40, eight out of ten Native American driver fatalities are in alcohol-related crashes is striking. Mexican Americans are also high with a 70\% involvement for that age group. Caucasian Americans with a 60\% alcohol involvement in that age group are slightly higher than both African Americans and the other Hispanic groups, and considerably higher than Asian-Pacific Islander Americans whose rate of alcohol involvement was less than $40 \%$. Despite the progress made during the 1980 s to reduce alcohol-related crashes among teenagers, during the 5-year period from 1990 to $1994,41 \%$ of the Caucasian American teenage driver deaths were in alcohol-related crashes. Both Native Americans and Mexican Americans had substantially higher rates of alcohol involvement, and Asian-Pacific Islander American teenagers had just over half the rate of the Caucasian American teenagers.

Table 7 provides information on the use of safety belts by vehicle occupants (drivers and passengers) in alcohol- and non-alcohol-related crashes. As can be seen for the fatalities in every ethnic group, individuals who were not wearing their safety belts were more likely to be in an alcohol-related crash than were those who wore belted. A total of $51 \%$ of fatally injured Caucasian American vehicle occupants who were not using safety belts were in alcohol-related crashes compared to only $30 \%$ of those who were wearing safety belts. For all ethnic groups, the majority of the vehicle occupants who died in vehicle crashes were not wearing belts. This is, of course, not surprising since safety belts provide a significant protective factor in the event of a crash. The fact that a greater percentage of those who were not wearing belts were in alcohol-related crashes is in keeping with previous studies that indicated drinking drivers are 
less likely to use safety belts. The differences in seat belt usage rates (between those with alcohol-positive drivers and those with alcohol-negative drivers) are shown in Figure 7.

FigURE 6. FATALLY INJURED DRIVERS IN ALCOHOL-RELATED CRASHES WHO HAD PREVIOUS

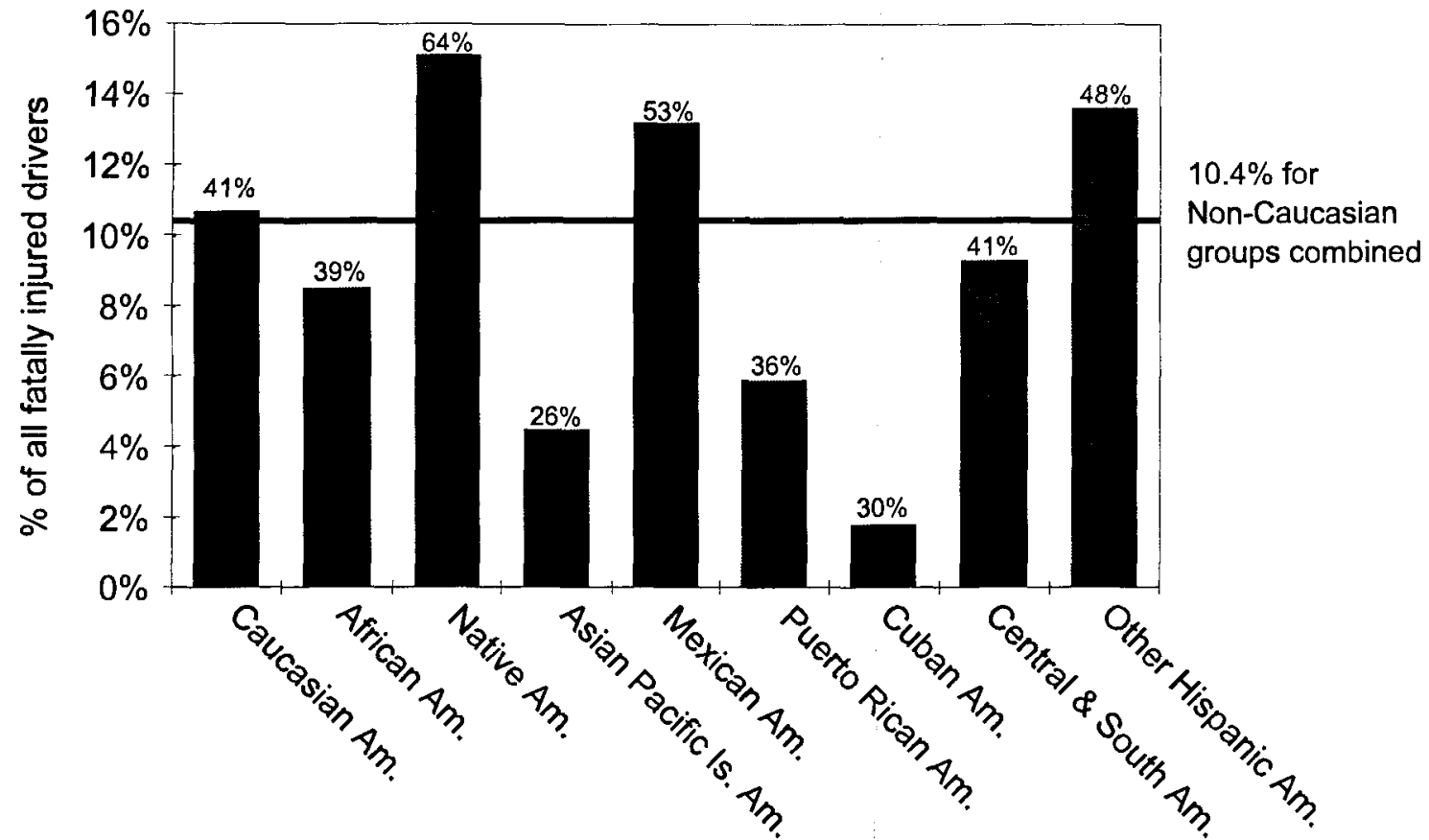

ALCOHOL-RELATED DRIVING OFFENSES ON THEIR RECORDS; PERCENTAGES ON TOPS OF BARS REFER TO KILLED DRIVERS WHO WERE ALCOHOL-POSITIVE (FARS: 1990 TO 1994)

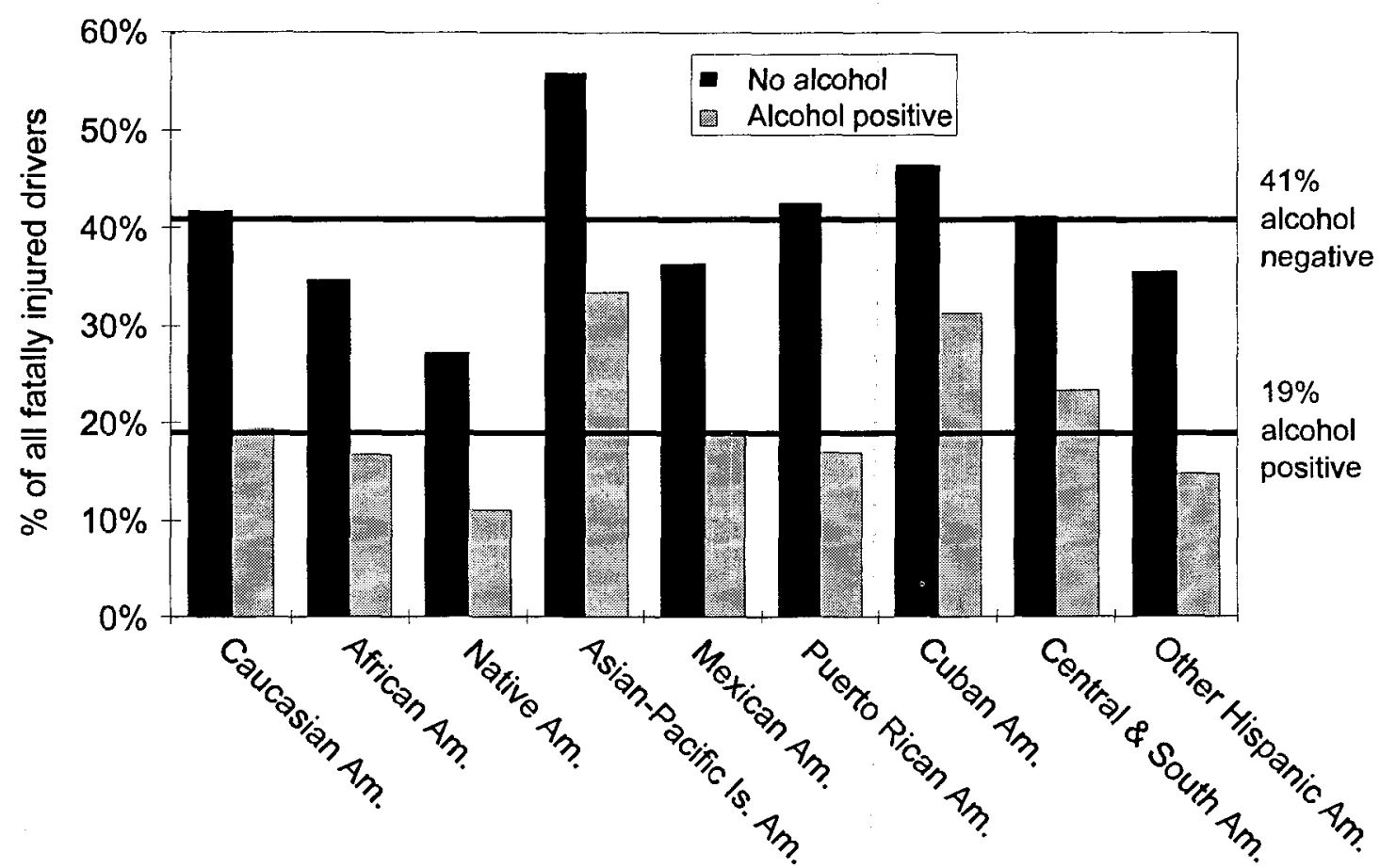

FIGURE 7. SAFETY BELT USAGE BY FATALLY INJURED DRIVERS WITH ZERO BACS AND POSITIVE BACS AT THE TIME OF THE CRASH (FARS: 1990 TO 1994) 


\section{DISCUSSION}

These data generally conform to the results reported in previous studies of ethnic groups' involvement in highway crashes. Native Americans have generally been found to be overinvolved in traffic crashes (Schiff \& Becker, 1996; Campos-Outcalt et al., 1997), and AsianPacific Islander Americans have generally been reported to have the lowest rates (NHTSA, 1998). These data, however, appear to provide the most valid basis for assessing the relative involvement of ethnic groups in alcohol-related crashes for these reasons: (1) they are based on official crash and death certificate data; (2) the use of total fatal crashes as a normalizing variable reduces the influence of factors such as VMT and socioeconomic status, which make interethnic group comparisons difficult; and (3) the definition of alcohol involved is based on actual measurements or objective estimating procedures rather than on self-reports.

Although this study has these strengths, it also has limitations: (1) the ethnic identifications come principally from next of kin, via funeral home directors, and may be subject to some error; (2) BAC measures are available on only a portion of the participants in fatal crashes $(60 \%$ to $70 \%$ of the fatally injured drivers)-BACs must be imputed based on crash characteristics for the rest; (3) almost no BAC data are available for passengers-their BAC status is assigned based on the BAC of the vehicle's driver; and (4) with only 5 years of data available, the numbers in some of the smaller ethnic groups (i.e., Puerto Ricans) are too small to provide fully reliable data. Despite these limitations, the FARS with death certificate information promises to provide the best picture currently available of the involvement of different ethnic groups in alcohol-related crashes. 
TABLE 4. ALCOHOL- AND NONALCOHOL-RELATED FATALITIES BY ETHNIC GROUP FROM 1990 TO 1994. DATA WEIGHTED FOR AGE DIFFERENCES.

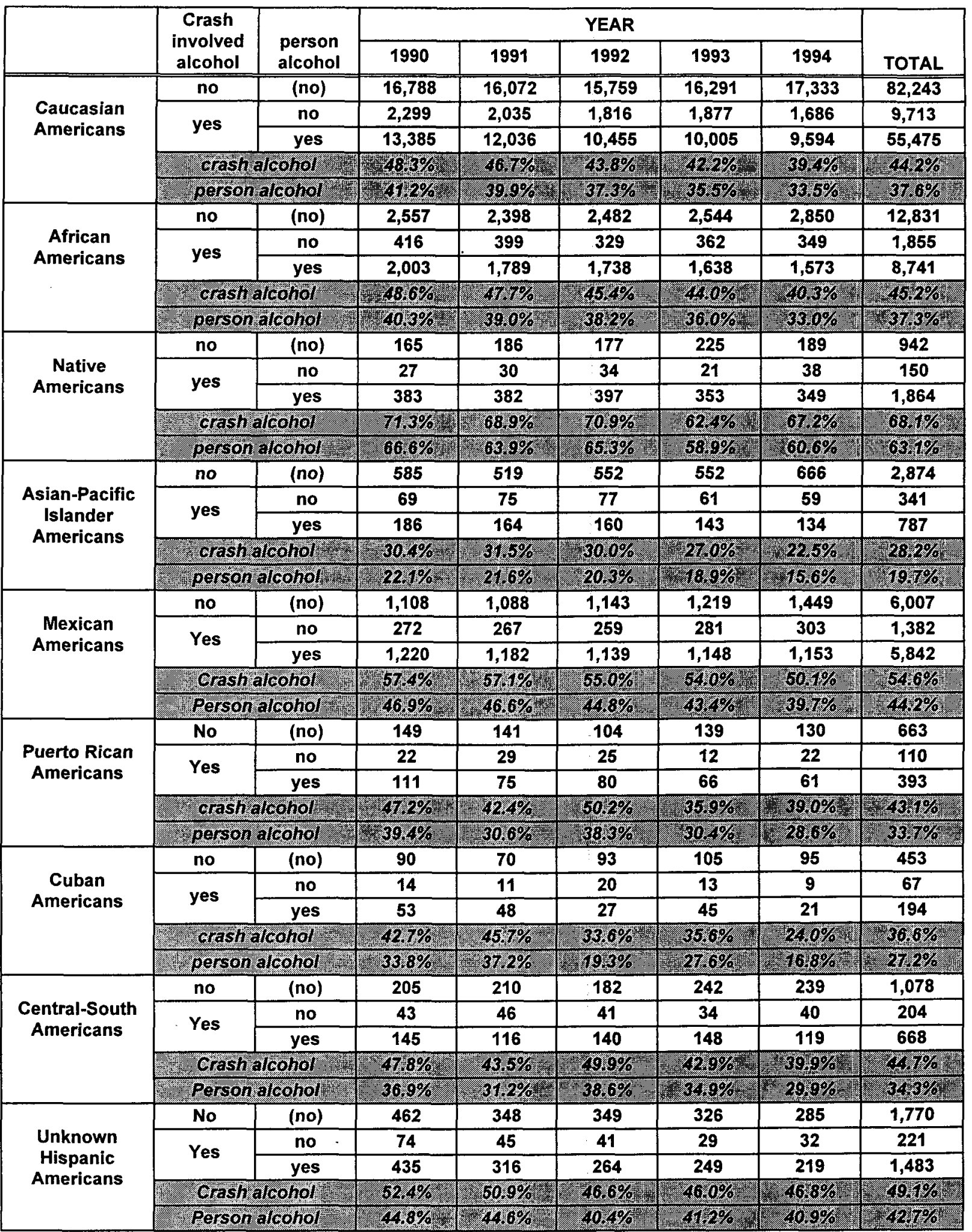


Ethnicity and Alcohol-Related Fatalities: 1990 to 1994

TABLE 5. ALCOHOL- AND NON-ALCOHOL-RELATED FATALITIES BY GENDER AND ROLE IN CRASH WEIGHTED FOR AGE DIFFERENCES BETWEEN ETHNIC GROUPS

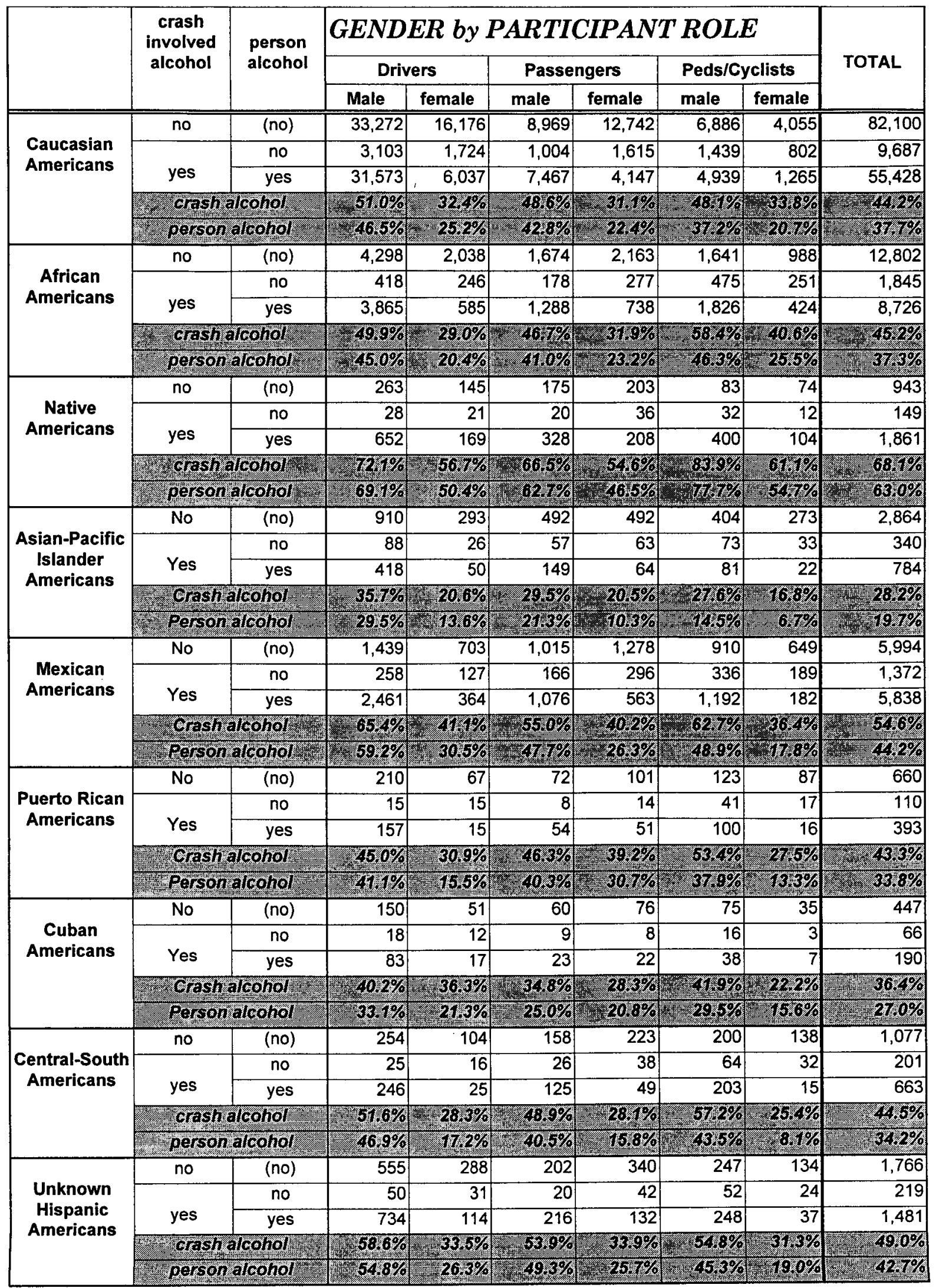


TABLE 6. ALCOHOL- AND NON-ALCOHOL-RELATED FATALLY INJURED DRIVERS BY AGE GROUP. WEIGHTED FOR GENDER DIFFERENCES BETWEEN AGE GROUPS.

\begin{tabular}{|c|c|c|c|c|c|c|c|c|c|c|c|}
\hline & \multirow{2}{*}{$\begin{array}{c}\text { crash } \\
\text { involved } \\
\text { alcohol } \\
\end{array}$} & \multirow{2}{*}{$\begin{array}{l}\text { person } \\
\text { alcohol }\end{array}$} & \multicolumn{8}{|c|}{ AGE (DRIVERS ONLY) } & \multirow[b]{2}{*}{ TOTAL } \\
\hline & & & $6-15$ & $16-20$ & $21-29$ & $30-39$ & $40-49$ & $50-59$ & $60-69$ & $70+$ & \\
\hline \multirow{5}{*}{$\begin{array}{l}\text { Caucasian } \\
\text { Americans }\end{array}$} & no & (no) & 600 & 7,901 & 8,190 & 7,018 & 5,948 & 4,763 & 5,090 & 9,931 & 49,443 \\
\hline & \multirow[b]{2}{*}{ yes } & no & 21 & 642 & 928 & 902 & 735 & 581 & 481 & 535 & 4,825 \\
\hline & & yes & 90 & 4,773 & 12,569 & 10,498 & 5,126 & 2,210 & 1,369 & 959 & 37,595 \\
\hline & 2. crostit & foothor & $15.6 \%$ & 1.507\% & $6 \% 2 \%$ & $167.67 \%$ & $796 \%$ & $30.96 \%$ & (1.26/ & $21 \% 1 \%$ & $1462 \%$ \\
\hline & Herson & toonol & $127 \%$ & $35 \%$ & $580 \%$ & $135 \% 0 \%$ & 2.46 $4 \%$ & $629.3 \%$ & 164,3976 & $6 x+8,4 \%$ & $\sqrt{100 \% 9 \%}$ \\
\hline \multirow{5}{*}{$\begin{array}{c}\text { African } \\
\text { Americans }\end{array}$} & no & (no) & 59 & 996 & 1,296 & 935 & 686 & 536 & 618 & 1,208 & 6,33 \\
\hline & \multirow[b]{2}{*}{ yes } & no & 6 & 87 & 167 & 122 & 85 & 69 & 51 & 77 & 66 \\
\hline & & yes & 4 & 497 & 1,420 & 1,120 & 622 & 325 & 233 & 224 & 4,44 \\
\hline & \multirow{2}{*}{\multicolumn{2}{|c|}{ 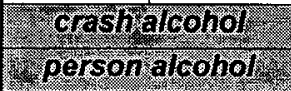 }} & 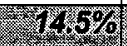 & 6700 & $56 \%$ & WT1 & $50.8 \%$ & 42.6 & $3175 \%$ & $190 \%$ & $0446 \%$ \\
\hline & & & $5=5.8 \%$ & 1) $315 \%$ & $1499 \%$ & $751.1 \%$ & $2417 \%$ & $34.9 \%$ & $258 \%$ & $148 \%$ & K $38.8 \%$ \\
\hline \multirow{5}{*}{$\begin{array}{c}\text { Native } \\
\text { Americans }\end{array}$} & no & (no) & 7 & 58 & 58 & 48 & 46 & 33 & 56 & 103 & 409 \\
\hline & \multirow[b]{2}{*}{ yes } & no & 2 & 8 & 10 & 9 & 7 & 5 & 5 & 2 & 48 \\
\hline & & yes & 9 & 127 & 248 & 211 & 115 & 45 & 36 & 31 & 822 \\
\hline & \multirow{2}{*}{\multicolumn{2}{|c|}{ 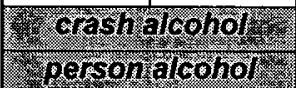 }} & $-61 \% 7 \%$ & 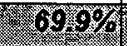 & 180760 & $82.1 \%$ & $1706 \%$ & $600 \%$ & 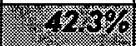 & $24,3 \%$ & $680 \%$ \\
\hline & & & $50.0 \%$ & $-6.58 \%$ & $170.5 \%$ & $7787 \%$ & (69) & $542 \%$ & $\sqrt[37]{3196}$ & $228 \%$ & $6643 \%$ \\
\hline \multirow{5}{*}{$\begin{array}{c}\text { Asian- } \\
\text { Pacific } \\
\text { Islander } \\
\text { Americans }\end{array}$} & no & (no) & 9 & 206 & 293 & 270 & 156 & 109 & 76 & 85 & 1,204 \\
\hline & & no & 0 & 6 & 37 & 34 & 22 & 10 & 4 & 2 & 115 \\
\hline & yes & yes & 1 & 57 & 156 & 127 & 82 & 31 & 9 & 5 & 468 \\
\hline & \multicolumn{2}{|c|}{ 2ripshyleotol } & $10.0 \%$ & $28.1 \%$ & 39978 & 37.9 & $400 \%$ & m. $3 \%$ & 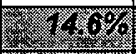 & $76 \%$ & $326 \%$ \\
\hline & \multicolumn{2}{|c|}{ 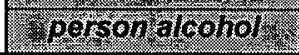 } & 10.096 & $8212 \%$ & 3.126 & $2905 \%$ & 3160 & 2079 & Tox & 56 & $226.2 \%$ \\
\hline \multirow{5}{*}{$\begin{array}{c}\text { Mexican } \\
\text { Americans }\end{array}$} & no & (no) & 35 & 364 & 426 & 355 & 278 & 189 & 199 & 295 & 2,141 \\
\hline & \multirow[b]{2}{*}{ yes } & no & 3 & 67 & 90 & 76 & 60 & 36 & 32 & 21 & 385 \\
\hline & & yes & 12 & 432 & 954 & 745 & 377 & 144 & 89 & 68 & 2,821 \\
\hline & \multirow{2}{*}{\multicolumn{2}{|c|}{$\frac{1 \text { crast halcohor }}{\text { person arcohel }}$}} & $300 \%$ & $.678 \%$ & $71,0 \%$ & 2008\% & $16717 \%$ & $48 \%$ & $37.8 \%$ & $28.2 \%$ & $600 \%$ \\
\hline & & & $240 \%$ & $50.1 \%$ & $6.9 .9 \%$ & 268.7 & $50.7 \%$ & $390 \%$ & $27.8 \%$ & $77.7 \%$ & $5.528 \%$ \\
\hline \multirow{5}{*}{$\begin{array}{c}\text { Puerto } \\
\text { Rican } \\
\text { Americans }\end{array}$} & no & (no) & 2 & 47 & 76 & 54 & 30 & 22 & 25 & 21 & 277 \\
\hline & \multirow[b]{2}{*}{ yes } & no & 0 & 3 & 12 & 9 & 2 & 1 & 2 & 0 & 29 \\
\hline & & yes & 0 & 19 & 60 & 55 & 24 & 5 & 4 & 3 & 170 \\
\hline & grasho & ohor f & $0.0 \%$ & $31.9 \%$ & $48.6 \%$ & 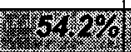 & $76.4 \%$ & $27 \%$ & 19798 & $128 \%$ & 3. $71.8 \%$ \\
\hline & person & & $2.0 .0 \%$ & 2758 & $120.5 \%$ & $46.6 \%$ & $176298 \%$ & 1790 & -1600 & $21,25 \%$ & $335.7 \%$ \\
\hline & no & (no) & 4 & 41 & 50 & 29 & 24 & 16 & 18 & 20 & 202 \\
\hline $\begin{array}{l}\text { Cuban } \\
\text { mericans }\end{array}$ & & no & 0 & 5 & 8 & 8 & 2 & 3 & 2 & 1 & 29 \\
\hline & yes & yes & 0 & 10 & 40 & 27 & 16 & 3 & \begin{tabular}{|r|}
3 \\
\end{tabular} & 2 & 101 \\
\hline & - crasho & colnorl? & $=0.0 \% \%$ & $26.8 \%$ & $190 \%$ & $2647 \%$ & $179.9 \%$ & $273 \%$ & (2) $7177 \%$ & W $130 \%$ & $10392 \%$ \\
\hline & person & forhot & $200 \%$ & $.17 .9 \%$ & $40.8 \%$ & $422 \%$ & 173819 & $136 \%$ & $718.0 \%$ & $30.67 \%$ & $304 \%$ \\
\hline & no & (no) & 4 & 60 & 81 & 66 & 54 & 27 & 36 & 26 & 354 \\
\hline $\begin{array}{l}\text { Central- } \\
\text { South }\end{array}$ & & no & 0 & 12 & 9 & 9 & 8 & 3 & 0 & 0 & 41 \\
\hline & yes & yes & 2 & 42 & 107 & 76 & 31 & 8 & 2 & 4 & 272 \\
\hline & orasha & Cohol & $35.3 \%$ & $47.4 \%$ & $=58 \% 9 \%$ & $56.3 \%$ & 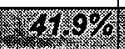 & $28.9 \%$ & $5.3 \%$ & $13 / 13 \%$ & $1346.9 \%$ \\
\hline & zperson & roohol & . $33.3 \%$ & $36.8 \%$ & $=54.3 \%$ & $50.3 \%$ & $38.3 \%$ & $21.1 \%$ & $.75 \%$ & (3) & $1408 \%$ \\
\hline & no & (no) & 12 & 140 & 135 & 113 & 105 & 81 & 83 & 172 & 841 \\
\hline Unknown & & no & 1 & 18 & 16 & 13 & 11 & 9 & 6 & 7 & 81 \\
\hline & yes & yes & 3 & 129 & \begin{tabular}{|l|}
286 \\
\end{tabular} & 221 & 112 & 44 & 34 & 17 & 846 \\
\hline & crasha & forhol: & $2050 \%$ & $5172 \%$ & $60.1 \%$ & 67.96 & 369\% & $906 \%$ & (5/,5\% & / $1 \% 2 \%$ & $5624 \%$ \\
\hline & person: & loohal & $18.8 \%$ & $4.9 .9 \%$ & $.65 .4 \%$ & $6.7 \%$ & $-49,196$ & $328 \%$ & $72,6 \%$ & $8.79 \%$ & $2.779 \%$ \\
\hline
\end{tabular}


TABLE 7. SAFETY BELT USAGE BY ALCOHOL- AND NON-ALCOHOL-RELATED FATALLY INJURED VEHICLE OCCUPANTS (FARS 1990 TO 1995). DATA WEIGHTED FOR AGE AND GENDER.

\begin{tabular}{|c|c|c|c|c|c|}
\hline & \multirow[t]{2}{*}{$\begin{array}{c}\text { Crash } \\
\text { involved } \\
\text { alcohol }\end{array}$} & \multirow[t]{2}{*}{$\begin{array}{l}\text { person } \\
\text { alcohol }\end{array}$} & \multicolumn{2}{|c|}{$\begin{array}{l}\text { SAFETY BELT } \\
\text { USED }\end{array}$} & \multirow[t]{2}{*}{ TOTAL } \\
\hline & & & No & yes & \\
\hline \multirow{4}{*}{$\begin{array}{l}\text { Caucasian } \\
\text { Americans }\end{array}$} & no & (no) & 38,692 & 26,134 & 64,826 \\
\hline & \multirow[b]{2}{*}{ yes } & no & 3,638 & 3,040 & 6,678 \\
\hline & & yes & 36,907 & 8,366 & 45,273 \\
\hline & \multicolumn{2}{|c|}{$\frac{\text { crash alcohol }}{\text { person Jicohol }}$} & 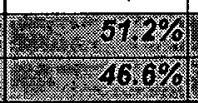 & $\frac{30 \% 9}{22,3 \%}$ & 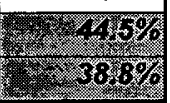 \\
\hline \multirow{4}{*}{$\begin{array}{l}\text { African } \\
\text { Americans }\end{array}$} & $\frac{\text { no }}{2}$ & (no) & 6,179 & 2,683 & $\begin{array}{r}8,862 \\
\end{array}$ \\
\hline & \multirow[b]{2}{*}{ yes } & no & 564 & 337 & 901 \\
\hline & & yes & 4,819 & 900 & 5,719 \\
\hline & 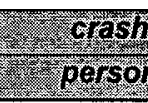 & contor, & $\begin{array}{l}106 \% \\
117 \%\end{array}$ & $\begin{array}{r}31.686 \\
230.0 \% 6\end{array}$ & $\frac{7.796}{36906}$ \\
\hline \multirow{4}{*}{$\begin{array}{l}\text { Native } \\
\text { Americans }\end{array}$} & no & (no) & 528 & 176 & 704 \\
\hline & \multirow[b]{2}{*}{ yes } & no & 77 & 20 & 97 \\
\hline & & yes & 1,127 & 129 & 1,256 \\
\hline & $\frac{c r a s s}{\text { perso }}$ & fornoly & $\frac{69}{66 \% 7 \%}$ & $\frac{40,0 \%}{99,2 \%}$ & 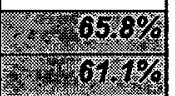 \\
\hline \multirow{4}{*}{$\begin{array}{l}\text { Asian-Pacific } \\
\text { Islander } \\
\text { Americans }\end{array}$} & no & (no) & 1,051 & 890 & 1,941 \\
\hline & \multirow[b]{2}{*}{ yes } & no & 95 & 107 & 202 \\
\hline & & yes & 415 & 181 & 596 \\
\hline & 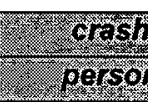 & conory & $\frac{327 \%}{266 \%}$ & 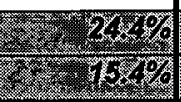 & $\frac{29,19}{2+18 \%}$ \\
\hline \multirow{4}{*}{$\begin{array}{c}\text { Mexican } \\
\text { Americans }\end{array}$} & no & (no) & 2,816 & $\frac{1,195}{1,19}$ & 4,011 \\
\hline & \multirow[b]{2}{*}{ yes } & no & 443 & 284 & 727 \\
\hline & & yes & 3,404 & 661 & 4,065 \\
\hline & $\frac{\text { crash }}{2 \text { persoi }}$ & $\frac{\text { lcohol }}{\text { Icohol }}$ & 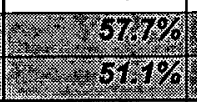 & 10\%9\% & 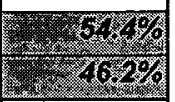 \\
\hline \multirow{4}{*}{$\begin{array}{l}\text { Puerto Rican } \\
\text { Americans }\end{array}$} & no & (no) & 268 & 134 & 402 \\
\hline & \multirow[b]{2}{*}{ yes } & no & 28 & 16 & 44 \\
\hline & & yes & 204 & 38 & 242 \\
\hline & $\begin{array}{l}\text { crash } \\
\text { persol }\end{array}$ & $\frac{\text { cohol }}{\text { Gohol }}$ & 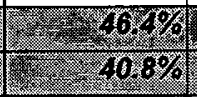 & $20.2 \%$ & (2. \\
\hline \multirow{4}{*}{$\begin{array}{l}\text { Cuban } \\
\text { Americans }\end{array}$} & no & (no) & 177 & 149 & 326 \\
\hline & \multirow[b]{2}{*}{ yes } & no & 24 & 20 & 44 \\
\hline & & yes & 92 & 46 & 138 \\
\hline & $\frac{\text { crash }}{\text { persol }}$ & $\begin{array}{l}\text { leohol } \\
\text { Tleohol }\end{array}$ & $\frac{39.6 \%}{2.37 \%}$ & 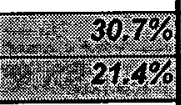 & \begin{tabular}{|l|}
$75 \%$ \\
$27.2 \%$
\end{tabular} \\
\hline \multirow{4}{*}{$\begin{array}{l}\text { Central-South } \\
\text { Americans }\end{array}$} & no & (no) & 429 & 220 & 649 \\
\hline & \multirow[b]{2}{*}{ yes } & no & 50 & 32 & 82 \\
\hline & & yes & 307 & 80 & 387 \\
\hline & 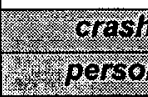 & $\frac{\text { Tlehol }}{\text { Tloohol }}$ & 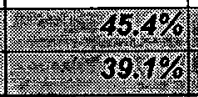 & 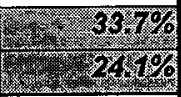 & 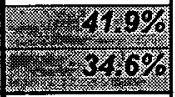 \\
\hline \multirow{4}{*}{$\begin{array}{l}\text { Unknown } \\
\text { Hispanic } \\
\text { Americans }\end{array}$} & no & (no) & 862 & 428 & 1,290 \\
\hline & \multirow[b]{2}{*}{ yes } & no & 81 & 54 & 135 \\
\hline & & yes & 958 & 160 & 1,118 \\
\hline & \multicolumn{2}{|c|}{$\begin{array}{l}\text { crash areohol } \\
\text { tr person alcohol }\end{array}$} & $\begin{array}{r}5 \%, 7 \% \\
50 \% \%\end{array}$ & $\frac{3}{1}-3.6 \%$ & $\frac{196 \%}{2.0 \%}$ \\
\hline
\end{tabular}




\section{REFERENCES}

Aty, M.A. and Radwan, A.E. (1998). Demographic factors and traffic crashes: Part 1Descriptive statistics and models. U.S. Department of Commerce, National Technical Information Service, Springfield, VA.

Baker, S.P., Braver, E.R., Chen, L., Pantula, J.F., and Massie, D. (1998). Motor vehicle occupant deaths among Hispanic and black children and teenagers. Archives of Pediatric Adolescent Medicine, Vol. 152, 1209-1212.

Bhopal, R. and Donaldson, L. (1998). Commentary: White, European, western, Caucasian, or what? Inappropriate labeling in research on race, ethnicity, and health. American Journal of Public Health, 88(9), 1303-1307.

Campos-Outcalt, D., Prybylski, D., Watkins, A.J., Rothfus, G., and Dellapenna, A. (1997). Motor-vehicle crash fatalities among American Indians and Non-Indians in Arizona, 1979-1988. American Journal of Public Health, 87(2), 282-285.

Castro, F.G., Hammond, W.R., John, R., Wyatt, G.E., and Yung, B.R. (1995). Panel IV: Risktaking and abusive behaviors among ethnic minorities. Health Psychology, 14(7), 622631.

Federal Highway Administration. (1998). Highway Statistics 1997. http://www.fhwa. dot.gov/ohim/hs97/dl1c.pdf.

Fullilove, M.T. (1998). Comment: Abandoning "race" as a variable in public health researchAn idea whose time has come. American Journal of Public Health, 88(9), 1297-1298.

Hahn, R.A. and Stroup, D.F. (1994). Race and ethnicity in public health surveillance: Criteria for the scientific use of social categories. CDC-ATSDR Workshop, 109(1), 7-15.

Klein, T. (1986). A method for estimating posterior BAC distributions for persons involved in fatal traffic accidents (DOT HS 807 094). Washington, DC: National Highway Traffic Safety Administration.

McKenney, N.R. and Bennett, C.E. (1994). Issues regarding data on race and ethnicity: The Census Bureau Experience. CDC-ATSDR Workshop. Public Health Reports, 109(1), 1625.

McKenney, N.R. and Cresce, A.R. (1993). Measurement of ethnicity in the United States:

Experiences of the U. S. Census Bureau. In Challenges of measuring an ethnic world: Science, politics and reality. Proceedings of the Joint Canada-United States Conference on the Measurement of Ethnicity, April 1-3, 1992. U.S. Government Printing Office, Washington, D.C., pp. 173-222.

National Highway Traffic Safety Administration. (Mar. 1998). Motor vehicle traffic crashes as a leading cause of death in the U.S., 1994. Technical Report, DOT HS 808687.

Robertson, L.S. (1992). The validity of self-reported behavioral risk factors: Seatbelt and alcohol use. The Journal of Trauma, 32(1), 58-59.

Ross, H.L., Howard, J.M., Ganikos, M.L., and Taylor, E.D. (1991). Drunk driving among American blacks and Hispanics. Accident Analysis and Prevention, 23(1), 1-11.

Sainz, S. and Saito, M. (1996). Hispanic involvement in motor vehicle accidents. Traffic and highway safety: Occupant restraints, safety management, and emergency and commercial vehicles, Transportation Research Record No. 1560. National Academy Press, Washington, DC, pp. 27-33. 
Schiff, M. and Becker, T. (1996). Trends in motor vehicle traffic fatalities among Hispanics, Non-Hispanic whites and American Indians in New Mexico, 1958-1990. Ethnicity \& Health, 1(3), 283-291.

Smith, P. and Remington, P. (1989). The epidemiology of drinking and driving: Results from the Behavioral Risk Factor Surveillance System. Health Education Quarterly, 16, 345-358.

Sugarman, J.R. and Grossman, D.C. (1996). Trauma among American Indians in an urban county. Public Health Reports, 3. 321-327.

Wallace, L.J.D., Sleet, D.A., and James, S.P. (Sept. 1997). Injuries and the ten leading causes of death for Native Americans in the U.S.: Opportunities for prevention. The IHS Provider, pp. 140-145. 
DOT HS 809068

June 2000

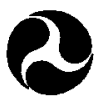

U.S. Department of Transportation

National Highway

Traffic Safety

Administration 